\title{
Atuação da Auditoria Interna nas Universidades Federais Brasileiras
}

Rodrigues, Rubens Carlos; Veras Machado, Marcus Vinicius

Atuação da Auditoria Interna nas Universidades Federais Brasileiras

Administração Pública e Gestão Social, vol. 13, núm. 4, 2021

Universidade Federal de Viçosa, Brasil

Disponible en: https://www.redalyc. org/articulo.oa?id=351568433006

\section{(c) $(1) \Theta$}

Esta obra está bajo una Licencia Creative Commons Atribución-NoComercial-SinDerivar 3.0 Internacional. 


\title{
Atuação da Auditoria Interna nas Universidades Federais Brasileiras
}

\author{
Performance of Internal Audit in Brazilian Federal Universities \\ El desempeño de la auditoría interna en las universidades federales brasileñas
}

\author{
Rubens Carlos Rodrigues \\ Mestre em Administração e Controladoria (UFC), Servidor \\ Público Federal (UFC), Brasil \\ rubenscarlos@fisica.ufc.br \\ Marcus Vinicius Veras Machado \\ Ph.D em Higher Education (University of Arizona/USA), \\ Professor Associado (UFC), Brasil \\ marcusmachado@ufc.br
}

Redalyc: https://www.redalyc.org/articulo.oa?

\section{Resumo:}

Objetivo da pesquisa: Analisar a atuação das Auditorias Internas, no âmbito das universidades públicas federais brasileiras, do ponto de vista da própria unidade.

Enquadramento teórico: A lente teórica utilizada é a Teoria Institucional, sob o ponto de vista de isomorfismo.

Metodologia: Esta pesquisa possui natureza qualitativa e descritiva, utilizando-se de análise documental dos dados obtidos por meio da Lei de Acesso a Informações, do Plano Anual de Atividades de Auditoria Interna e Relatório Anual de Atividades de Auditoria Interna, relacionados ao ano de 2016, organizados e tabulados por meio do software Excel'.

Resultados: Nas 60 universidades federais pesquisadas foram planejadas 1.052 atividades e os resultados obtidos demonstram que as atividades desenvolvidas visam os Controles da Gestão e possuem como foco, principalmente, as auditorias de gestão e operacional. Mais de um terço das atividades desenvolvidas estão ligadas ao assessoramento a gestores, acompanhamento da implementação de recomendaçôes dos órgãos de controle e emissão de relatórios, demonstrando a proatividade deste departamento com a gestão.

Originalidade: Evidenciar as práticas deste órgão, possibilitando uma análise mais detalhada de sua atuação.

Contribuiçôes teóricas e práticas: Comprova que o foco dos trabalhos desenvolvidos pela Auditoria Interna moderna consiste em avaliar o processo de gestão de riscos e governança da entidade no intuito de atender as necessidades da organização e assessorála, apresentando dados empíricos mais detalhados e estudos comparativos sobre a extensão dos tipos de auditoria e as suas práticas.

Palavras-chave: Terceira linha de defesa, Universidade Pública, Controle Interno, Setor Público.

\section{Abstract:}

Research Objective: Analyze the performance of Internal Audits, within the scope of Brazilian federal public universities, from the point of view of the unit itself.

Theoretical framework: The theoretical lens used is Institutional Theory, from the point of view of isomorphism.

Methodology: This research has a qualitative and descriptive nature, using documentary analysis of the data obtained through the Access to Information Law, the Annual Internal Audit Activities Plan and the Annual Internal Audit Activities Report, related to the year 2016, organized and tabulated using Excel ${ }^{\circ}$ software.

Results: In the 60 federal universities surveyed, 1,052 activities were planned and the results obtained demonstrate that the activities developed are aimed at Management Controls and are mainly focused on management and operational audits. More than a third of the activities carried out are linked to advising managers, monitoring the implementation of recommendations from the control bodies and issuing reports, demonstrating the proactivity of this department with management.

Originality: Evidence the practices of this body, allowing a more detailed analysis of its performance.

Theoretical and practical contributions: It proves that the focus of the work carried out by the modern Internal Audit is to evaluate the risk management and governance process of the entity in order to meet the needs of the organization and advise it, presenting more detailed empirical data and comparative studies on the extension of types and its practices. 
KEYWORDS: Third line of defense, Public university, Internal control, Public sector.

\section{RESUMEN:}

Objetivo de la investigación: Analizar el desempeño de las Auditorías Internas, en el ámbito de las universidades públicas federales brasileñas, desde el punto de vista de la propia unidad.

Marco teórico: La lente teórica utilizada es la Teoría Institucional, desde el punto de vista del isomorfismo.

Metodología: Esta investigación tiene un carácter cualitativo y descriptivo, mediante el análisis documental de los datos obtenidos a través de la Ley de Acceso a la Información, el Plan Anual de Actividades de Auditoría Interna y el Informe Anual de Actividades de Auditoría Interna, relacionados con el año 2016, organizado y tabulado con el software Excel ${ }^{\circ}$.

Resultados: En las 63 universidades federales encuestadas se planificaron 1.052 actividades y los resultados obtenidos demuestran que las actividades desarrolladas están dirigidas a los Controles de Gestión y están enfocadas principalmente a las auditorías de gestión y operativas. Más de un tercio de las actividades desarrolladas están vinculadas a asesorar a los responsables, dar seguimiento a la implementación de las recomendaciones de los órganos de control y emitir informes, demostrando la proactividad de este departamento con la dirección.

Originalidad: Evidenciar las prácticas de este organismo, permitiendo un análisis más detallado de su desempeño.

Contribuciones teóricas y prácticas: Demuestra que el enfoque del trabajo que realiza la Auditoría Interna moderna es evaluar el proceso de gestión y gobernanza de riesgos de la entidad con el fin de atender las necesidades de la organización y asistirla, presentando datos empíricos más detallados y estudios comparativos sobre la extensión de los tipos y sus prácticas.

Palabras clave: Tercera línea de defensa, Universidad pública, Control interno, Sector público.

\section{INTRODUÇÃo}

As unidades de auditorias do setor público foram instituídas com o intuito de analisar os mecanismos de controle em utilização nas instituições (Rodrigues, 2019), constituindo uma importante ferramenta de avaliação quanto à aplicação dos recursos públicos pelos gestores e sociedade, possibilitando o acompanhamento no uso eficiente e correto, seja pelo Sistema de Controle Interno (SCI) das instituições ou pela própria população (Fonseca, Jorge, \& Nascimento, 2020).

O papel tradicional da Auditoria Interna (AUDIN) sempre direcionou ao monitoramento do controle interno e da conformidade financeira, no entanto, cada vez mais requer-se a função de consultoria interna nas instituições e atuação no gerenciamento de riscos (Alzeban \& Gwilliam, 2014; Dias, Gomes, Angonese, \& Quintana, 2020). Tal mudança impulsionou a criação de novas habilidades para realização de atividades relacionadas ao gerenciamento de riscos e governança corporativa, visando incrementar o valor adicionado pela AUDIN às necessidades específicas da entidade (Arena \& Azzone, 2009).

A AUDIN, como parte da estrutura de governança nas Instituições de Ensino Superior (IES), é empregada como um mecanismo para auxiliar o gerenciamento no controle dos recursos da instituição e na qualidade da educação (Silva \& Sena, 2019), visando harmonizar os interesses e expectativas da sociedade (principal) com a atuação dos gestores públicos (agentes) na entidade (Pinheiro \& Oliva, 2020)

Identificar os riscos emergentes e buscar ações para mitigá-los é extremamente necessário às entidades, face às mudanças nos cenários econômicos, no ambiente regulatório ou no próprio negócio (KPMG, 2017), e visam a possibilidade de ser ampliada a profundidade da análise de dimensões como relevância e criticidade no planejamento das atividades e agregar valor à gestão (Rodrigues, 2019).

Dada a quantidade de universidades públicas, do volume de recursos financeiros movimentados por estas instituições e a exigência que os seus gestores utilizem, eficazmente, ferramentas de transparência no controle dos recursos públicos, as AUDINs têm buscado efetuar revisões em seus controles internos e nas metodologias de trabalho, para que as ações desenvolvidas por estas unidades também sejam transparentes (Moreira \& Palmisano, 2016). Diante o exposto, a problemática da pesquisa é: Como as Auditoria Internas atuam nas universidades públicas federais brasileiras? Assim, o objetivo deste estudo consiste em analisar a atuação da AUDIN no âmbito das universidades federais brasileiras, do ponto de vista da própria unidade. 
À medida que os parâmetros de controles internos são identificados e avaliados, possibilita o desenvolvimento de ações necessárias no processo de melhoria na auditagem governamental, tornando mais seguros e efetivos o planejamento e o SCI, possibilitando um maior controle social. Assim, esta pesquisa se propõe a identificar, publicizar e a discutir academicamente as práticas profissionais adotadas no universo das auditorias internas pertencentes às universidades federais brasileiras.

Beuren e Zonatto (2014, p. 3) afirmam que pesquisas acadêmicas envolvendo o SCI na área pública apresentam muitas oportunidades, pois a compreensão da sua estrutura e "os fatores que podem favorecer a implementação de um ambiente eficaz de controle neste setor são temas que carecem de maior investigação", também refletindo sobre as práticas adotadas na execução das atividades e contribuindo no fortalecimento da AUDIN (Dias et al., 2020)

Adiciona-se a estes fatores a incipiência de produção científica envolvendo auditoria no âmbito governamental, tanto em nível nacional (Beuren \& Zonatto, 2014) quanto internacional (Mafra, Suave, Guilherme, \& Alberton, 2015), bem como pela relevância da temática nas instituições públicas, pois "cumpre uma função fundamental, pois permite à administração melhorar a sua gestão para alcançar os objetivos públicos e os fins sociais que perseguem a instituição" (Chacón, 2015, p. 128).

Dias et. al. (2020) buscaram analisar o processo de institucionalização da AUDIN em uma universidade federal e, dentre os achados, verificaram que há a necessidade de esclarecer as finalidades e a forma de atuação desta unidade. Pinheiro e Oliva (2020) analisaram a atuação da AUDIN na governança, do ponto de vista da alta administração, composta por reitores, vice-reitores, pró-reitores de Administração e próreitores de Planejamento. Assim, a presente pesquisa justifica-se por analisar a atuação da AUDIN sob a perspectiva interna desta unidade, e visando complementar as pesquisas anteriores, tendo como foco central a publicização das atividades realizadas em seus relatórios e como a AUDIN está se adaptando aos normativos vigentes e às orientações oriundas de pesquisas acadêmicas, buscando, conforme Power (2003), apresentar dados empíricos mais detalhados e estudos comparativos sobre a extensão dos tipos de auditoria e as suas práticas.

\section{Referencial Teórico}

Nesta seção serão apresentados tópicos relacionados à atuação da AUDIN, os tipos e as áreas de Auditoria utilizados na área pública, os quais são imprescindíveis para analisar, neste trabalho, os trabalhos desenvolvidos pela AUDIN e, para finalizar, estudos empíricos já realizados em Auditoria Interna e que estavam relacionados às instituições de ensino.

\subsection{Atuação da Auditoria Interna}

Conforme a Instrução Normativa (IN) Conjunta n. 01, de 10 de maio de 2016, a AUDIN deve exercer "atividade independente e objetiva de avaliação e de consultoria, desenhada para adicionar valor e melhorar as operações de uma organização", no intuito de contribuir com a entidade "a realizar seus objetivos, a partir da aplicação de uma abordagem sistemática e disciplinada para avaliar e melhorar a eficácia dos processos de gerenciamento de riscos, de controles internos, de integridade e de governança" (Instrução Normativa Conjunta n. 01, 2016).

O papel da AUDIN assume mais relevância no contexto da Administração Pública Federal, pois além de avaliar as áreas definidas nesta instrução, deve buscar também a eficiência destas e assessorá-las na mitigação dos riscos e no alcance das metas e objetivos traçados pela alta direção em seu planejamento estratégico.

No intuito de aumentar a eficácia da AUDIN e fornecer melhorias e segurança das informações, esta unidade deve planejar as suas atividades aspirando a melhoria da produtividade, avaliando a consistência dos 
resultados alcançados com os objetivos estabelecidos, examinando o SCI e o gerenciamento de risco (Alzeban \& Gwilliam, 2014).

O objetivo da auditoria que está sendo estruturada deve ser claro e entendido por todos os auditores, pois é de fundamental importância para execução do planejamento e do direcionamento dos serviços a serem desenvolvidos (Pickett, 2005). Castro (2015, p. 481) afirma que em toda auditoria realizada há algum grau de risco envolvido ocasionado por "dúvida sobre a consistência das evidências, sobre a efetividade dos controles internos, a fidedignidade dos valores apresentados nas demonstrações financeiras ou veracidade dos fatos informados nos relatórios de gestão", devendo ser minimizados a níveis aceitáveis, cabendo aos gestores a mensuração dos riscos e o seu controle.

A auditoria não somente avalia os processos de controle, mas também o processo de gestão de riscos e a governança da organização. Castro (2015, p. 482) afirma que a Auditoria Baseada em Risco (ABR) "busca direcionar o foco do trabalho, a fim de avaliar as tendências e as condições que a entidade possui para atingir seus resultados", alterando, assim, o perfil do auditor, que era preparado para fazer avaliação dos processos e ações do passado, levando-o a concentrar-se mais nos resultados a serem alcançados. Pickett (2005) afirma que uma avaliação corporativa dos riscos envolve quatro aspectos: definição da própria unidade de auditoria, avaliações dos riscos envolvidos em cada unidade auditável, levantamento sobre as falhas já detectadas e classificação dos riscos elaborando um plano de auditoria.

Resultados positivos serão alcançados caso os gestores estejam cônscios dos riscos relacionados às suas unidades, possibilitando que os mesmos atuem de forma a melhor alocar e maximizar os recursos disponíveis e adotando os controles necessários na execução das atividades. A implementação da ABR na gestão pública é estimulada pelos órgãos de controle, tanto o Ministério da Transparência e Controladoria Geral da União (CGU) quanto o Tribunal de Contas da União (TCU), intentando o fortalecimento do SCI na Administração Pública e constituindo uma importante ferramenta para avaliar os riscos nas entidades (Rodrigues, 2019).

Com o intuito de identificar as áreas de maior significância e riscos, ou seja, passíveis de auditoria, o TCU elaborou no ano de 2005 a Resolução n. 185, que definiu fatores de risco, materialidade, relevância e oportunidade como critérios para escolha de tais áreas, em que Castro (2015) e Rodrigues (2019) corroboram com esta hierarquização e priorização dos trabalhos de auditoria. Desta forma, há a necessidade de se aliar a materialidade a outros indicadores de risco (relevância e criticidade) para assim determinar as atividades passíveis de auditoria e priorizar processos a serem auditados em detrimento de outros.

O mapeamento das atividades auxilia no seu detalhamento e orienta no processo de hierarquização dos programas, ações e atividades, com o fito de apurar o risco inerente à priorização das atividades a serem realizadas. Após esse mapeamento, deve-se realizar uma pontuação para cada um destes itens e construir uma matriz de riscos, na qual as ações que alcançarem maiores pontuações deverão ser priorizadas na realização das auditorias (Chaves, 2011; Castro, 2015). A elaboração da matriz de riscos visa orientar o planejamento dos trabalhos da AUDIN, produção de informações gerenciais, auxílio no processo de tomada de decisões e principalmente conhecer e avaliar o SCI da entidade.

As AUDINs podem utilizar vários instrumentos para o planejamento das suas atividades, sendo os mais importantes o Plano Anual de Atividades de Auditoria Interna (PAINT) e o Relatório Anual de Atividades de Auditoria Interna (RAINT) (Rodrigues, 2019), os quais visam tornar mais transparente a atuação da AUDIN. No processo de planejamento e elaboração do PAINT devem estar contemplados os planos e objetivos da entidade, programas e ações conforme orçamento próprio; a legislação relacionada; os resultados das últimas auditorias realizadas, tanto pela CGU, TCU e da própria AUDIN. Há também as próprias demandas internas da unidade e do corpo técnico disponível para execução das atividades (Instrução Normativa Conjunta n. 01, 2016; Instrução Normativa n. 09, 2018).

A Instrução Normativa da CGU (IN CGU) 24/2015, e, posteriormente, a IN CGU 09/2018, que a atualizou e que está em vigência, estabeleceu que o planejamento das atividades devem ser classificadas 
empregando uma matriz de risco (Instrução Normativa n. 24, 2015; Instrução Normativa n. 09, 2018), a qual deve ser elaborada considerando os macroprocessos existentes, sendo necessário um mapeamento de todos os processos identificados, mantendo-se assim uma visão panorâmica dos riscos envolvidos e sua magnitude, ou os temas passíveis de serem trabalhados, em conformidade com as perspectivas de materialidade, criticidade e relevância (Instrução Normativa Conjunta n. 01, 2016; Rodrigues, 2019).

O levantamento dos temas ou macroprocessos a serem trabalhados requer conhecer, na entidade auditável, quais os produtos que serão gerados e qual a contribuição para a sociedade (missão, valores, planejamento estratégico, gerenciamento de riscos, dentre outros). Para isso, a AUDIN pode utilizar como instrumentos de identificação entrevistas, reuniões e aplicação de questionários com os gestores da entidade. Ao observar estes pontos, busca-se com o PAINT realizar o planejamento em seu nível tático, sendo necessário ainda elaborar o planejamento operacional dos seus trabalhos de auditoria, definindo assim o escopo, objetivos, critérios de análise, dentre outros. Power (2003) enfatiza que a definição da função do escopo e da função da auditoria fazem parte do processo de institucionalização desta unidade interna às instituições.

As entidades também devem emitir relatórios de desempenho, os quais buscam atender a expectativa dos diversos usuários e enfatizar a importância das suas atividades no contexto em que estão inseridos (Power, 2019). A emissão do RAINT caracteriza uma prestação de contas da AUDIN frente à gestão da entidade e aos órgãos superiores e, após a publicação nos sítios eletrônicos, para todos os interessados, além de ser apropriado como autoavaliação da própria unidade, tendo que detalhar todas as atividades realizadas pela AUDIN, seja de acompanhamento, avaliações, assessoramento à alta administração ou auditorias preventivas, acrescentando também os fatos relevantes de natureza administrativa que impactaram no desenvolvimento das atividades, as ações de capacitação dos servidores lotados neste órgão (Instrução Normativa n. 09, 2018; Rodrigues, 2019).

A adoção de práticas que sejam comuns às diversas AUDINs é esperada, conforme a Teoria Institucional, haja vista as pressões exercidas pelos órgãos reguladores, assim como do ambiente institucional nas quais estão inseridas, levando à prática do isomorfismo em busca de legitimação e a competitividade. DiMaggio e Powel (1991) identificaram três perspectivas: isomorfismo coercitivo (pressões, formais ou informais, exercidas por agentes externos à instituição), isomorfismo mimético (adoção de práticas adotadas em outras organizações como respostas a incertezas oriundas da baixa compreensão das regras) e isomorfismo normativo (estabelecimento de normas e regras, seja no âmbito social ou profissional).

\subsection{Tipos e Áreas de Auditoria}

Peter e Machado (2014) esmiúçam vários campos de trabalho possíveis em auditoria no setor público e aspectos que devem ser considerados quando do planejamento das atividades, cujos tipos de auditoria estão sintetizados na Tabela 1. 
Tabela 1 - Tipos de Auditoria

\begin{tabular}{l|l}
\hline Tipo & Foco \\
\hline Gestão & $\begin{array}{l}\text { Verificar a regularidade dos atos e fatos feitos pelos } \\
\text { administradores. }\end{array}$ \\
\hline $\begin{array}{l}\text { Acompanhamento da } \\
\text { Gestão }\end{array}$ & Atuar em tempo real os trabalhos de Auditoria de Gestão. \\
\hline Programas & $\begin{array}{l}\text { Identificar e avaliar a aplicação dos recursos públicos, } \\
\text { conforme programa e projetos governamentais. }\end{array}$ \\
\hline Contábil & $\begin{array}{l}\text { Verificar os registros contábeis e a fidedignidade das } \\
\text { informações geradas. }\end{array}$ \\
\hline $\begin{array}{l}\text { Operacional ou } \\
\text { desempenho }\end{array}$ & $\begin{array}{l}\text { Assessorar o gestor público, avaliando ações gerenciais e } \\
\text { procedimentos operacionais. }\end{array}$ \\
\hline Sistemas & $\begin{array}{l}\text { Avaliar os sistemas de informática e as informações } \\
\text { produzidas por eles. }\end{array}$ \\
\hline Qualidade & $\begin{array}{l}\text { Estímulo a cultura gerencial no serviço público e identificar os } \\
\text { pontos fortes e fracos da entidade. }\end{array}$ \\
\hline Especial & $\begin{array}{l}\text { Atender determinação de autoridade competente, cujos } \\
\text { trabalhos não estão contemplados nos demais tipo. }\end{array}$ \\
\hline
\end{tabular}

Fonte: Elaborado conforme Castro (2015, p. 450); Chaves (2011, p. 21); Peter e Machado (2014, p. 102). Importar tabla

Os tipos de auditoria apresentados na Tabela 1 representam o enfoque dado pela equipe quando do momento da verificação documental e conforme o propósito motivacional, no entanto, Chaves (2011, p. 39) e a IN Conjunta do Ministério do Planejamento, Orçamento e Gestão e a CGU 01/2016 abordam a divisão da gestão pública em áreas distintas a serem trabalhadas, as quais são: Controles de Gestão, Gestão Orçamentária, Gestão Financeira, Gestão de Recursos Humanos, Gestão Patrimonial, Gestão de Suprimento de Bens e Serviços e Gestão Operacional, conforme Tabela 2.

Tabela 2 - Áreas de Auditoria

\begin{tabular}{l|l}
\hline Área & Foco \\
\hline Controles de Gestão & $\begin{array}{l}\text { Monitorar os gestores no cumprimento das determinações } \\
\text { oriundas dos órgãos de controle, podendo para isso utilizar } \\
\text { Sistemas informatizados }\end{array}$ \\
\hline Gestão Orçamentária & $\begin{array}{l}\text { Verificar se as receitas e as despesas, tanto de capital como } \\
\text { Correntes, estão sendo executadas conforme a finalidade do } \\
\text { programa estabelecido }\end{array}$ \\
\hline Gestão Financeira & $\begin{array}{l}\text { Análise está nos recursos da entidade, englobando os } \\
\text { disponiveis, realizáveis e os exigiveis, bem como as } \\
\text { demonstraçôes contábeis }\end{array}$ \\
\hline Gestão de Recur'sos & $\begin{array}{l}\text { Apreciação dos atos funcionais relacionados aos agentes } \\
\text { públicos, iniciando com o provimento da vaga atéa a } \\
\text { aposentadoria }\end{array}$ \\
\hline Gumanos & $\begin{array}{l}\text { Levantamento, acompanhamento e responsabilização dos } \\
\text { bens, móveis ou imóveis, da entidade }\end{array}$ \\
\hline Gestão de Suprimento de & $\begin{array}{l}\text { Verificar os processos necessários e estabelecidos quando } \\
\text { da compra ou contratação por parte do poder público e a } \\
\text { Sua obediência à legislação de licitaçôes e contratos }\end{array}$ \\
\hline Gestão operviços & $\begin{array}{l}\text { Avaliação das açôes gerenciais e de seus procedimentos } \\
\text { operacionais nos aspectos relacionados a eficiência, } \\
\text { eficácia, economicidade, efetividade e qualidade }\end{array}$ \\
\hline
\end{tabular}

Fonte: Elaborado conforme Chaves (2011); Instrução Normativa Conjunta n. 01 (2016). Importar tabla 
Esta divisão por áreas de funcionamento serve para seccionar a atuação das auditorias e melhorar o controle da gestão pública, tendo em vista sua complexidade e amplitude, sendo adotada pela CGU quando da realização de suas auditorias.

\subsection{Estudos correlatos}

Brito, Pimenta, Souza e Cruz (2017) buscaram identificar os benefícios e desafios na implantação da ABR nas IES. Os dados para a pesquisa foram obtidos por meio de questionário aplicado a auditores internos destas instituições e, em seguida, tratados estatisticamente com a utilização da técnica de análise fatorial para extrair fatores que representassem grupos de benefícios e desafios na implantação da ABR. Os autores constataram que a gestão de riscos era um tema recente no contexto da gestão pública universitária, sendo necessário incentivar e promover a cultura de gestão de riscos visando a modernização da administração pública brasileira. Por meio da técnica de análise fatorial obteve-se que dois fatores ("Consolidação da gestão de riscos" e "Aperfeiçoamento da comunicação e monitoramento de auditorias") representavam benefícios e três fatores ("Aspectos normativos", "Falta de apoio da alta administração" e "Estrutura de gestão de riscos inadequada") representavam desafios na implantação da ABR.

Fonseca, Jorge e Nascimento (2020) discutiram a associação entre accountability e auditoria interna, analisando até que ponto a última contribui para melhorias na primeira, nas Instituições de Ensino Superior (IES) públicas portuguesas. O estudo baseou-se nos resultados de questionários enviado aos órgãos de gestão de uma amostra de IES. Dentre os achados, têm-se que a auditoria interna serve à accountability, promovendo os seus princípios; as informações geradas pela AUDIN contribuem para melhorar a eficácia da gestão e ajudar na tomada de decisões e a boa governança da organização.

O processo de institucionalização da auditoria interna em uma universidade federal, na perspectiva de auditores e gestores, foi objeto de estudo de Dias et al. (2020), os quais realizaram entrevistas com auditores e gestores da alta administração e análise de documental de uma IES. Os resultados indicaram baixa aderência ao estágio de habitualização (tentativa de desenvolver procedimentos padronizados para a manutenção e o funcionamento das atividades organizacionais) e moderada aos estágios de objetificação (frequente atividade de teorização por grupos de interesse, buscando atribuir à estrutura legitimidade cognitiva e normativa, com a difusão da estrutura deixa de ocorrer exclusivamente por processos miméticos e passa a ter uma base mais normativa) e sedimentação (difusão da estrutura é virtualmente completa, tanto pela sua propagação no ambiente, como pela sua perpetuação) do processo de institucionalização; indicaram a necessidade de esclarecer as finalidades e a forma de atuação do setor na universidade, de incrementar o processo de acompanhamento das recomendações emitidas e de ampliar o acesso a programas e sistemas de informação.

Pinheiro e Oliva (2020) analisaram a atuação da auditoria interna na governança das universidades públicas federais brasileiras, do ponto de vista da alta administração, composta por reitores, vice-reitores, pró-reitores de Administração e pró-reitores de Planejamento. Utilizando de uma pesquisa quantitativa descritiva, com uma amostra de 33 universidades, e qualitativa, através da técnica de coleta de dados Focus Group, os resultados evidenciaram que as diretrizes para boas práticas de governança corporativa não são plenamente adotadas pelas universidades públicas federais, tendo em vista que muitas das determinações são expressas por intermédio de leis e regulamentos. Apontaram, também, que a maioria da Alta administração concorda que a auditoria interna auxilia a universidade na execução de suas estratégias, sendo uma importante instância interna de apoio à governança da universidade. 


\section{Procedimentos Metodológicos}

A presente pesquisa é considerada, quanto à sua natureza, como descritiva. Quanto aos procedimentos adotados, pode-se classificá-la como documental e, quanto à abordagem, entendeu-se que analisar as atividades da AUDIN é um evento qualitativo, tendo em vista empregar somente a estatística descritiva (Beuren, 2014).

A população objeto deste estudo compreende as universidades públicas federais brasileiras identificadas e vinculadas ao Ministério da Educação (MEC), conforme busca realizada no sítio eletrônico e-MEC, responsável pela base de dados oficiais e única de informações relativas às IES, no dia 13 de março de 2017.

Para coletar os dados necessários para a realização desta pesquisa, utilizou-se de dados secundários documentos (PAINT e RAINT) emitidos pela população estudada e relacionados ao ano de 2016 - assim como de dados primários, obtidos utilizando solicitação de informações do Sistema Eletrônico do Serviço de Informação ao Cidadão (e-SIC).

$\mathrm{O}$ ano de 2016 foi escolhido para análise nesta pesquisa pois entraram em vigência dois importantes normativos que alteravam o funcionamento da AUDIN nas entidades públicas: A IN CGU n. 24/2015, que estabelecia o planejamento das atividades utilizando uma matriz de risco, e a IN Conjunta MP/CGU n. 01, que dispunha sobre controles internos, gestão de riscos e governança no âmbito do Poder Executivo Federal.

Ao considerar os prazos estipulados e vincendos, pelos normativos da CGU, para disponibilização dos relatórios PAINT e RAINT, relacionados ao ano de 2016, nos sítios eletrônicos das universidades, temse que o PAINT deveria ser disponibilizado até o último dia útil de dezembro de 2015 para aprovação do Conselho de Administração ou a instância equivalente ou, inexistindo, o dirigente máximo do órgão ou entidade e enviado para a CGU até o último dia útil de fevereiro de 2016. Quanto ao RAINT, a AUDIN deveria apresentá-lo ao Órgão de Controle Interno, após apreciação pelo Conselho de Administração ou equivalente, até o último dia útil de fevereiro de 2017 e publicá-lo na internet em local de fácil acesso em até 30 dias após a conclusão.

Assim, no dia 13 de março de 2017 foi efetuada buscas no sítio eletrônico "Google", com demanda de palavras-chave "PAINT 2016", "RAINT 2016" e "Universidade" "X", onde "X" é o nome da universidade, sendo direcionado para o conteúdo pesquisado, caso houvesse. Como resultado foi considerado insatisfatório numa população de 63 Universidades, foi então solicitada, no mesmo dia 13 de março de 2017, via e-SIC, o envio dos relatórios PAINT e RAINT não encontrados nos sítios eletrônicos. Os dados obtidos, tanto utilizando a internet como via solicitação E-SIC, podem ser sintetizados na Tabela 3.

Tabela 3 - Relatórios PAINT e RAINT obtidos para a pesquisa

\begin{tabular}{l|l|l|l}
\hline Operação & Descrição & Universidades & $\%$ \\
\hline$(=)$ & Sujeitos da pesquisa & 63 & $100,00 \%$ \\
\hline \multirow{2}{*}{$-)$} & $\begin{array}{l}\text { Universidades que estavam implantando } \\
\text { AUDIN no ano de 2016 }\end{array}$ & 2 & $3,17 \%$ \\
\hline$(-)$ & Universidade que não elaborou PAINT / RAINT & 1 & $1,59 \%$ \\
\hline$=$ & $\begin{array}{l}\text { Total de PAINT / RAINT para análise das } \\
\text { atividades }\end{array}$ & 60 & $\mathbf{9 5 , 2 4 \%}$ \\
\hline & $\begin{array}{l}\text { PAINT disponibilizado na Internet em } \\
13 / 03 / 2017\end{array}$ & 25 & $41,67 \%$ \\
\cline { 2 - 4 } & PAINT obtido via E-SIC & 35 & $58,33 \%$ \\
\hline \multirow{2}{*}{} & $\begin{array}{l}\text { RAINT disponibilizado na Internet em } \\
13 / 03 / 2017\end{array}$ & 8 & $13,33 \%$ \\
\cline { 2 - 4 } & RAINT obtido via E-SIC & 52 & $86,67 \%$ \\
\hline
\end{tabular}

Fonte: Dados da pesquisa. 
O período do recebimento dos relatórios não disponíveis nos sítios eletrônicos das universidades ficou compreendido entre as datas 13 de março de 2017 e 22 de dezembro de 2017. As 60 universidades participantes da amostra desta pesquisa disponibilizaram ambos os relatórios solicitados, possibilitando assim confrontar as ações planejadas no PAINT com as evidenciadas como realizadas, ou não, no RAINT. Em 1 universidade localizada na região Nordeste alegou-se que, devido a dificuldades adversas na AUDIN, não foi elaborado o relatório PAINT para o ano pesquisado.

No intuito de descrever os métodos empregados para a definição de quais as atividades a serem realizadas pelas unidades de auditoria interna, coletou-se os dados considerados quando do planejamento das auditorias, no relatório PAINT, para o ano de 2016, para tornar possível o mapeamento das atividades e a sua hierarquização, sendo verificada a descrição dos critérios considerados para a elaboração do planejamento e a apresentação da metodologia para a seleção das atividades a serem realizadas, caso apresentasse estes aspectos, as informações, etapas e critérios seriam transpostos para planilha eletrônica.

Para identificar e coletar as atividades planejadas pela AUDIN, no relatório PAINT foram extraídas as ações e os objetivos pretendidos com aquela ação. Para identificar as ações desenvolvidas pela AUDIN no ano de 2016, foi consultado o relatório RAINT e extraídos os seguintes dados: a) As atividades evidenciadas como realizadas, independente de anterior planejamento; b) Caso a atividade não tenha sido realizada ou não concluída, coletada a justificativa e a previsão de conclusão ou de realização.

Ao término da coleta de dados, buscou-se agrupar os dados colhidos através da utilização de terminologias padrão e conforme as similaridades encontradas permitindo assim uma melhor análise, sendo organizados e tabulados por meio de planilha eletrônica e para cada ação de auditoria e consoante o objetivo pretendido com aquela atividade, utilizando-se de análise documental, foram efetuadas as seguintes classificaçóes, conforme a Tabela 4:

Tabela 4 - Classificação das ações de Auditoria, conforme Tipos e Áreas

\begin{tabular}{c|c}
\hline Tipos de Auditoria & Áreas de Auditoria \\
\hline Gestão & Controles de Gestão \\
\hline Acompanhamento da Gestão & Gestão Orçamentária \\
\hline Programas & Gestão Financeira \\
\hline Contábil & Gestão de Recursos Humanos \\
\hline Operacional ou desempenho & Gestão Patrimonial \\
\hline Sistemas & Gestão de Suprimento de Bens e Serviços \\
\hline Qualidade & Gestão Operacional \\
\hline Especial & \\
\hline
\end{tabular}

Fonte: Elaborado pelo autor conforme Castro (2015); Chaves (2011); Peter \& Machado (2014).

Estas classificações permitem identificar quais são as áreas e os tipos de auditoria que são priorizados por estas unidades ao desenvolverem as suas atividades. Todos estes processos foram entendidos como necessários para analisar a atuação da AUDIN em todo o contexto organizacional e assim poder melhor interpretar os resultados obtidos.

\section{Resultados E Discussões}

Este segmento da pesquisa expõe a análise e interpretação dos dados coletados, conforme explicado na seção anterior. 


\subsection{Critérios para o planejamento das atividades}

A Tabela 5 contém dados relacionados ao planejamento das atividades, obtidos nos 60 relatórios PAINT analisados, demonstrando o isomorfismo normativo exercido nas universidades analisadas, tendo em vista a aplicação do pilar normativo, por meio da Instrução Normativa (IN) 24/2015, e visando uma maior profissionalização deste campo organizacional, assim como disseminar boas práticas (DiMaggio \& Powel, 1991).

Tabela 5 - Planejamento das atividades

\begin{tabular}{lcc}
\hline Característica & Qtde. & $\mathbf{\%}$ \\
\hline Critérios para elaboração do PAINT & 55 & $91,67 \%$ \\
\hline Exposição da metodologia no PAINT & 38 & $63,33 \%$ \\
\hline Apresentação da Matriz de Risco & 40 & $66,67 \%$ \\
\hline
\end{tabular}

Conforme a Tabela 5, em 55 (91,67\%) universidades foi apresentado o detalhamento dos critérios para elaboração do PAINT, sendo que em 5 (8,33\%) PAINTs as informações contidas nestes relatórios eram somente relacionadas às ações de auditoria planejadas, sem maiores detalhes sobre os critérios adotados para o mapeamento das atividades e confecção da Matriz de Risco.

Para que o processo de escolha e planejamento das atividades fique compreensível, faz-se necessário demonstrar a metodologia adotada e a Matriz de Risco utilizada para poder hierarquizar as ações analisadas (Rodrigues, 2019). Conforme a Tabela 5, 40 (66,37\%) universidades apresentam a matriz de risco adotada, nas outras 20(33,33\%) instituições não é possível afirmar sobre a utilização da Matriz de Risco ou qualquer outro método para priorizar as atividades, tendo em vista que não foi evidenciado no PAINT tal uso, estando em desacordo com a IN CGU 24/2015, sendo que 15(25\%) relatórios foram somente citados os fatores considerados da seleção das atividades, sem exposição da metodologia utilizada e nem a Matriz de Risco considerada; em 2 (3,33\%) relatórios houve a citação dos critérios, exposição da metodologia, mas não foi apresentada a matriz de risco; e em 3 (5,00\%) relatórios foram apresentados somente os critérios e a matriz de risco, sem demonstrar a metodologia no PAINT todos os procedimentos utilizados, tornando as informações constantes nos relatórios imprecisas.

O processo de identificação de situações que envolvem risco e auxílio no processo de tomada de medidas concretas que permitam mitigá-las, bem como imputar responsabilidades em situações de falhas asseguram que a AUDIN forneça um suporte importante para os órgãos gestores, reforçando o controle e a confiança inerentes às suas funções (Fonseca et al., 2020).

Para a construção da Matriz de Risco e a definição de quais as atividades seriam selecionadas, em 47 (78,33\%) universidades este processo contou somente com a atuação da AUDIN. Em 4 (6,67\%) universidades, além da participação dos auditores também houve a aplicação de questionários a gestores das áreas, nos níveis estratégico, tático e operacional, no intuito de priorizar as ações baseadas não somente na visão do auditor, mas ponderando os riscos inerentes a cada área sob a ótica do gestor responsável. Em $1(1,67 \%)$ universidade, além dos questionários, os auditores também se reuniram com os gestores. Em 8 (13,33\%), além dos critérios considerados pelos auditores, houve também reunião com os gestores, sem aplicação de questionário.

A participação de membros externos à AUDIN no processo de planejamento e identificação dos riscos visa despertar nos gestores a importância de estarem cientes dos riscos que estão sujeitos no desenvolvimento das suas atividades e, com isso, colaborar para que façam uma melhor gestão de riscos no seu setor e AUDIN alinhe as suas atividades com o apetite a risco estabelecido pela entidade (Rodrigues, 2019).

O planejamento das ações e a utilização da classificação de riscos partindo de uma visão mais ampla da entidade, a qual é proporcionada pela utilização dos Macroprocessos, foi utilizada em nove (15,00\%) 
universidades e nas demais 51 (85,25\%) baseou-se nos temas passíveis de serem trabalhados, observando a sua materialidade, criticidade e relevância.

$\mathrm{Na}$ Tabela 5 também consta que, dentre as 38 (63,33\%) universidades que demonstraram a metodologia, em 28 foram apresentadas as mesmas características de calcular a Matriz de Risco, conforme a materialidade, criticidade e relevância, chamada de Matriz de Risco básica. Em quatro utilizam-se do modelo de Auditoria Baseada em Risco elaborado e desenvolvido pela Fundação Universidade Federal do ABC (UFABC), com adaptações para atender as necessidades da própria universidade. A Fundação Universidade Federal do Pampa (UNIPAMPA) e a Fundação Universidade Federal de Pelotas (UFPEL) utilizam o método Matriz de Análise de Processos Críticos (MAPC). Enquanto a Universidade Federal da Fronteira Sul (UFFS) e a Universidade Federal de Minas Gerais (UFMG) cada uma elaborou a matriz de risco distinta e conforme os seus critérios. Maiores detalhes da construção destas matrizes de riscos podem ser obtidos no trabalho de Rodrigues (2019).

Verifica-se que algumas universidades estão padronizando as Matrizes de Risco, conforme modelos vigentes e adotados em outras unidades, percebendo-se assim uma busca de uniformização e demonstrando a existência de isomorfismo mimético (DiMaggio \& Powel, 1991), haja vista que há um processo de reprodução de práticas e visando enfrentar as incertezas e incompletudes do normativo que estabeleceu a adoção de matrizes de risco, mas não definiu o modelo a ser implementado nas instituições. Deste modo, por meio do isomorfismo normativo está ocorrendo o isomorfismo mimético, visando a implementação de padrões e legitimar as ações desenvolvidas nas auditorias internas.

\subsection{Atividades planejadas}

Ao agregar as 1.052 ações, identificadas no PAINT por área de auditoria, conforme metodologia detalhada por Chaves (2011), tem-se a Tabela 6.

Tabela 6 - Atividades planejadas conforme a área de Auditoria

\begin{tabular}{l|l|l|l|l}
\hline Área de Auditoria & Qtde. ações & $\mathbf{\%}$ & Horas & $\mathbf{\%}$ \\
\hline $\begin{array}{l}\text { Controles da gestão } \\
\begin{array}{l}\text { Suprimento de bens e } \\
\text { Serviços }\end{array}\end{array}$ & 475 & $45,15 \%$ & 153.318 & $40,32 \%$ \\
\hline Operacional & 171 & $16,25 \%$ & 70.856 & $18,64 \%$ \\
\hline Recursos Humanos & 119 & $11,69 \%$ & 61.285 & $16,12 \%$ \\
\hline Patrimonial & 57 & $11,31 \%$ & 46.231 & $12,16 \%$ \\
\hline Financeira & 45 & $5,42 \%$ & 16.898 & $4,44 \%$ \\
\hline Orçamentária & 34 & $4,28 \%$ & 11.867 & $3,12 \%$ \\
\hline Reserva Técnica & 28 & $3,23 \%$ & 8.271 & $2,18 \%$ \\
\hline Total Geral & $\mathbf{1 . 0 5 2}$ & $2,66 \%$ & 11.492 & $3,02 \%$ \\
\hline
\end{tabular}

Os próximos parágrafos tecem comentários relacionados à Tabela 6, sendo que 1.052 atividades foram previstas nas 60 universidades pesquisadas, conforme os dados coletados no PAINT, sendo que a Universidade Federal do Rio Grande do Sul (UFRGS) a que mais evidenciou, 28 ações, ao passo que a Universidade Federal de Santa Catarina (UFSC) e a Universidade Federal Rural do Semi-Árido (UFERSA) somente demonstraram nove ações planejadas para o ano de 2016.

Mesmo não consistindo em uma área de auditoria, 18 (30,00\%) universidades reservaram uma determinada quantidade de horas, as quais denominaram de "Reserva Técnica", tendo em vista o atendimento a ações não contempladas no PAINT, que pudessem surgir sem que tenha havido possibilidade de previsão de datas e carga horária, assim como atividades que exijam dedicação maior do que foi planejado. Em três universidades, essa reserva foi destinada a ações de assessoramento à administração. 
A maior parte das ações $(45,15 \%)$ e das horas $(40,32 \%)$ está relacionada a Controles da Gestão, ações que envolvem, dentre outras, o acompanhamento do cumprimento das recomendações ou determinações constantes nos relatórios de auditoria, assessoramento a órgãos e a elaboração dos seus relatórios e do parecer do relatório de gestão. Desse modo, o papel da AUDIN assegura o cumprimento dos normativos legais e regulamentos internos existentes e assessora os órgãos de gestão (Fonseca et al., 2020).

As auditorias em atividades envolvendo o Suprimento de Bens e Serviços englobam quase todos os pagamentos efetuados pela administração, e abrange, conforme dados que constam nos relatórios analisados, auditoria nos processos de convênios, acordos, contratos de repasse, assim como os processos licitatórios, no intuito de aferir o cumprimento da legislação pertinente e a correta aplicação dos recursos públicos nos processos de contratação ou aquisição de bens e serviços, cujo resultado esperado é a clara formalização dos processos, em cumprimento às exigências legais.

A área Operacional compreende a avaliação e o acompanhamento da execução da programação dos objetivos e metas da entidade, eficiência e eficácia de aplicação dos recursos públicos e aprimoramento dos controles e da responsabilidade gerencial. Nesta pesquisa verificou-se que as ações visavam a atividade fim da universidade, abrangendo indicadores de desempenho e a estrutura dos cursos de graduação e pós-graduação, assim como a atuação dos docentes e discentes no âmbito acadêmico.

Avaliar os aspectos da legalidade e legitimidade no gerenciamento dos Recursos Humanos foi planejado em 47 (78,33\%) universidades e consiste em analisar a confiabilidade dos controles internos quanto aos atos relacionados à folha de pagamento, ações de desenvolvimento institucional e capacitação prevista para o fortalecimento da atividade da AUDIN. Vale destacar que a subárea Capacitação e Desenvolvimento não foi citada por nenhuma instituição na pesquisa em 2010 (Farias, Schulz, Bellato, \& Alberton, 2012), demonstrando assim a necessidade de capacitação deste departamento para poder melhor desenvolver as atividades frente às novas exigências, legais e de boas práticas.

As atividades envolvendo a área Orçamentária visam comprovar a conformidade da execução dos programas previstos no orçamento anual da entidade, com os limites e destinações estabelecidas nas legislações pertinentes atestando o nível de execução das metas, o alcance dos objetivos e a adequação do gerenciamento, constando no planejamento de 18 (30,00\%) universidades.

Quanto à área Patrimonial, compóe-se em verificar o cumprimento de normas internas específicas a este setor e avaliar o grau de confiabilidade e fidedignidade dos registros e dos mecanismos de controle quanto à identificação, à localização, à movimentação e ao estado de conservação dos bens móveis e imóveis, assim como dos materiais alocados nos almoxarifados e a utilização de veículos oficiais e fornecimento dos combustíveis, estando presente no planejamento de $36(60 \%)$ universidades.

As atividades ligadas à área Financeira, evidenciadas em 26 (43,33\%) PAINTs, consistem, em sua grande maioria, em avaliar a concessão de suprimento de fundos na entidade, levando em conta os aspectos relacionados à autorização e aplicação dos recursos, à análise das despesas e à aprovação, no intuito de melhorar o processo como um todo em relação à eficiência, economicidade e eficácia dos recursos públicos, evitando a utilização indevida do cartão corporativo.

Os dados até aqui apresentados relacionados à Tabela 6 contrastam com a pesquisa de Farias, Schulz, Bellato e Alberton (2012), que verificaram no ano de 2010 que as áreas auditadas pelas AUDIN eram prioritariamente, nesta ordem, Suprimento de bens e serviços, Gestão Patrimonial e Gestão de recursos Humanos, as quais possuíam maior complexidade para os auditores. Com isso, percebe-se que a mudança de paradigma, onde os controles relacionados a gestão correspondem a $45 \%$ das atividades planejadas na presente pesquisa e corroboram com os achados de Pinheiro e Oliva (2020), em que $81,3 \%$ da alta administração concorda que a auditoria interna auxilia a universidade, com a sua atuação flexível e alinhada com a estratégia estabelecida pela entidade.

Ao analisar o objetivo e a finalidade das ações, estas puderam ser classificadas nos tipos de auditoria descritos conforme estabelecido na Tabela 1 e expostos na Tabela 7. 
Tabela 7 - Atividades planejadas conforme o tipo de Auditoria

\begin{tabular}{l|c|c|c|c}
\hline \multicolumn{1}{c|}{ Tipos de Auditoria } & Qtde. ações & $\mathbf{\%}$ & Horas & \% \\
\hline Gestão & 515 & $48,95 \%$ & 183.916 & $48,37 \%$ \\
\hline Operacional & 237 & $22,53 \%$ & 89.748 & $23,60 \%$ \\
\hline Acompanhamento da gestão & 115 & $10,93 \%$ & 37.745 & $9,93 \%$ \\
\hline Qualidade & 71 & $6,75 \%$ & 26.041 & $6,85 \%$ \\
\hline Contábil & 31 & $2,95 \%$ & 9.213 & $2,42 \%$ \\
\hline Treinamentos / Cursos / Eventos & 31 & $2,95 \%$ & 13.937 & $3,67 \%$ \\
\hline Reserva Técnica & 28 & $2,66 \%$ & 11.492 & $3,02 \%$ \\
\hline Programas & 12 & $1,14 \%$ & 4.204 & $1,11 \%$ \\
\hline Sistemas & 11 & $1,05 \%$ & 2.472 & $0,65 \%$ \\
\hline Especial & 1 & $0,10 \%$ & 1.450 & $0,38 \%$ \\
\hline Total Geral & $\mathbf{1 . 0 5 2}$ & $\mathbf{1 0 0 , 0 0 \%}$ & $\mathbf{3 8 0 . 2 1 8}$ & $\mathbf{1 0 0 , 0 0 \%}$ \\
\hline
\end{tabular}

Conforme a Tabela 7 e os achados de Cruz (2007) e Castro (2015), a Auditoria de Gestão tem como objetivo verificar a legalidade dos atos praticados e avaliar os resultados operacionais quanto aos objetivos e metas afixados, identificando os desvios relevantes e buscando a maior eficiência dos sistemas de controle em todas as universidades.

A Auditoria Operacional consiste na avaliação de programas e políticas públicas, com a finalidade de aferir os resultados obtidos por meio da atuação da entidade, tornando a gestão pública voltada para resultados. Estas avaliações podem ser reconhecidas como insumo a serem utilizadas na tomada de decisão sobre a formulação de programas e políticas públicas, bem como na sua reestruturação, quando for necessário, contribuindo para o aperfeiçoamento da gestão. O resultado a ser alcançado está vinculado ao sentido de valor público, corroborando os achados no contexto português, no qual o papel da AUDIN consiste em avaliar a performance da entidade tendo em conta os princípios da economia, eficácia e eficiência (Fonseca et al., 2020).

Os dois tipos de auditoria mencionados anteriormente foram planejados por todas as AUDINs analisadas e demonstram a preocupação destas unidades em realizar atividades voltadas à finalidade estratégica da entidade.

Em 54 (90,00\%) universidades foram evidenciadas atividades de Auditoria de Acompanhamento de gestão, as quais buscam atuar como departamento de consultoria e assessoramento às demais unidades e à alta administração, no desempenho de suas funções, dotando-os de informações confiáveis para tomada de decisões, mitigando a possibilidade de incorreções e assegurando a adequação dos atos de gestão à legislação pertinente e aos resultados, quanto à economicidade, eficiência e eficácia da Gestão Orçamentária, Financeira, Patrimonial e de Pessoal. Esse avanço nas condições de trabalho visa trazer segurança para os próprios gestores da entidade e deve-se à crescente intensificação dos processos de responsabilização dos gestores na Administração Pública e constitui um fator que tem contribuído para diminuir as resistências ao trabalho realizado pela AUDIN (Dias et al., 2020).

Em 33 (55,00\%) universidades foram evidenciadas práticas da Auditoria de Qualidade, envolvendo a identificação dos pontos fortes e fracos, falhas e sugestões, propostas de ações de fortalecimento da própria AUDIN e uma maior aproximação com a gestão, bem como atividades que busquem dinamizar os trabalhos no decorrer dos exercícios.

A Auditoria Contábil foi planejada em 18 (30,0\%) universidades, consistindo em examinar e emitir parecer sobre as demonstrações contábeis e a sua conformidade com os princípios da Administração Pública, assim como averiguar a legalidade e a tempestividade dos registros e informações contidos nos documentos dos processos relacionados a parte financeira dos atos praticados pela gestão.

A Auditoria de Sistemas consiste em verificar os registros das informações provindas dos sistemas eletrônicos de processamento de dados, analisando o ambiente computacional, a segurança das informações 
e os controles internos da entidade, identificando as deficiências e os pontos fortes, com recomendações de saneamento das mesmas e constou no PAINT de 21 (35,00\%) universidades.

A realização de Auditoria Especial foi planejada em 1 única universidade, possuindo como finalidade a análise das Tomadas de Contas Especiais e emissão de Parecer do Tomador de Contas Especial, conforme estabelece o Decreto n. 3.591/2000.

\subsection{Realização das atividades}

Tão logo seja concluído o exercício anual, as AUDINs devem emitir relatório de atividades, realizadas ou não, e ao contrapor as atividades planejadas e evidenciadas no PAINT com as atividades que constam no RAINT, buscando associar as atividades que constavam em ambos os relatórios, tem-se a seguinte realidade da Figura 1.

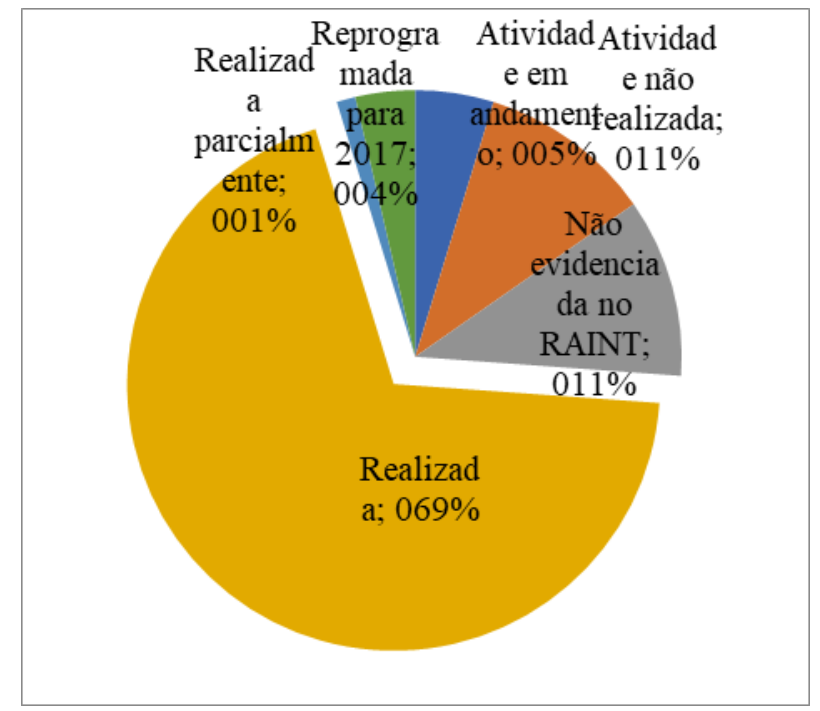

Figura 1 - Atividades planejadas, conforme o PAINT, e evidenciadas no RAINT

Com base nas 1.052 ações previstas no PAINT, 727 (69,11\%) foram iniciadas e concluídas durante o exercício de 2016. As 38 (3,61\%) atividades que foram reprogramadas para 2017 se referiam a atividades não realizadas no ano de 2016 e que foram incluídas no PAINT, ano calendário de 2017, para serem executados, ao passo que as demais 62 atividades não concluídas, poderão ou não ser executadas no próximo exercício, mas não constavam no relatório PAINT 2017.

Em 50 (4,75\%) atividades ainda estavam em andamento, ou seja, foram iniciadas no ano de 2016 e durante a elaboração do RAINT ainda estava sendo desenvolvidas. Em $12(1,14 \%)$ ações foram evidenciadas como realizadas parcialmente, pois mesmo iniciando as atividades, não foi demonstrado no RAINT se as mesmas estavam em andamento ou tinham realizados somente uma parte, para posterior prosseguimento, sendo apresentadas justificativas para 49 ações, dentre as 62.

Mesmo com previsão no PAINT, 114 (10,84\%) ações não foram evidenciadas no RAINT, seja como atividade realizada, não realizada ou não concluída. Tal situação foi constatada em 27 (45,00\%) universidades, quatro destas em percentual maior que 50\% em relação às atividades planejadas.

As 727 (69,17\%) ações realizadas em 2016 e previstas no PAINT, ao serem evidenciadas no RAINT, 251 (34,53\%) informaram a quantidade de servidores que participaram da execução, $129(17,74 \%)$ as horas gastas efetivamente e 324 (44,57\%) apresentaram o cronograma despendido para cumprir o planejamento, destas, 227 informaram as datas de início e término das atividades. Ao comparar estes três aspectos quando da evidenciação do planejamento das atividades no PAINT, tem-se os seguintes percentuais: $62,17 \%, 88,69 \%$ 
e 89,45\%, respectivamente. Estas três características foram demonstradas conjuntamente no RAINT em 5 (8,33\%) universidades, enquanto em 26 (43,33\%) entidades nenhum destes aspectos foi divulgado. Nas demais $29(48,33 \%)$ ao menos uma destas características foi exposta. Tal diferença não permite assim a confrontação entre planejado e executado, na maioria das ações, quanto a estes aspectos, não permitindo avaliar a eficiência da unidade.

$\mathrm{Na}$ Tabela 8 estão listadas todas as atividades realizadas, concluídas ou não, as quais foram identificadas nos relatórios mencionados e apresentadas conforme ordem de frequência. Este agrupamento foi possível devido a ocorrência de isomorfismo mimético entre as instituições, tornando possível esta agregação em torno de padrões, haja vista que uma mesma sentença poderia ser escrita de diferentes maneiras, no entanto, possuíam a mesma finalidade.

Tabela 8 - Atividades evidenciadas no RAINT como realizadas

\begin{tabular}{|c|c|c|}
\hline Atividade & Qtde. & $\%$ \\
\hline $\begin{array}{l}\text { Atendimento e acompanhamento das auditorias, recomendações e } \\
\text { determinações do TCU / CGU / Auditoria Interna / Conselhos } \\
\text { Superiores. }\end{array}$ & 150 & $16,15 \%$ \\
\hline Elaboração do PAINT / RAINT / Exame e Parecer do Relatório de Gestão & 149 & $16,04 \%$ \\
\hline Folha de pagamento & 87 & $9,36 \%$ \\
\hline Convênios / Contratos & 60 & $6,46 \%$ \\
\hline Assessoramento e orientações & 60 & $6,46 \%$ \\
\hline Licitaçốes & 56 & $6,03 \%$ \\
\hline Gestão do Patrimônio & 48 & $5,17 \%$ \\
\hline Avaliação dos controles internos & 43 & $4,63 \%$ \\
\hline Auditoria Interna - Trabalhos internos ao setor & 43 & $4,63 \%$ \\
\hline Cumprimento das Metas previstas no PPA / LDO & 27 & $2,91 \%$ \\
\hline Treinamentos / Cursos / Eventos & 25 & $2,69 \%$ \\
\hline Discentes & 22 & $2,37 \%$ \\
\hline Obras e instalaçốes & 21 & $2,26 \%$ \\
\hline Outros & 21 & $2,26 \%$ \\
\hline Gestão acadêmica & 18 & $1,94 \%$ \\
\hline Reserva Técnica & 13 & $1,40 \%$ \\
\hline Gestão Ambiental / Sustentabilidade & 12 & $1,29 \%$ \\
\hline Tecnologia da informaçấo - Infraestrutura e gestão & 10 & $1,08 \%$ \\
\hline Apuramento de denúncia recebida & 10 & $1,08 \%$ \\
\hline Indicadores de desempenho & 10 & $1,08 \%$ \\
\hline Atuação Ouvidoria / E-SIC & 9 & $0,97 \%$ \\
\hline $\begin{array}{l}\text { Avaliação e acompanhamento da execução da programação dos } \\
\text { objetivos e metas da Entidade }\end{array}$ & 9 & $0,97 \%$ \\
\hline Auditoria Baseada em Riscos $(\mathrm{ABR})$ & 8 & $0,86 \%$ \\
\hline Suprimento de Fundos - Cartões Corporativos & 7 & $0,75 \%$ \\
\hline Sistemas integrados da APF & 6 & $0,65 \%$ \\
\hline $\begin{array}{l}\text { Avaliar regularidade dos processos de sindicância e Processo } \\
\text { Administrativo Disciplinar }\end{array}$ & 5 & $0,54 \%$ \\
\hline Total Geral & 929 & $100 \%$ \\
\hline
\end{tabular}

O acompanhamento dos atos executados pelos gestores no tocante ao atendimento das recomendações emanadas pelos órgãos de controle quando da realização de auditorias e também a verificação das ações que estão sendo desenvolvidas para cumprimento das metas apresentadas no Plano de Providência Permanente (PPP) para sanar as constatações apresentadas por meio de notas de auditoria, bem como o suporte necessário aos auditores dos órgãos de controle para a realização de seus trabalhos na Instituição foram as atividades mais evidenciadas como realizadas pelas unidades de Auditoria Interna no RAINT. Esse acompanhamento é necessário para melhorar o índice de implementação das recomendações emitidas pelo setor, sendo necessário o aprimoramento das práticas relacionadas ao acompanhamento das recomendações (Dias et al., 2020). 
A confecção dos relatórios visando atender as legislações específicas foi evidenciada em 55 (91,67\%) RAINTs, nos quais buscam efetuar planejamento das ações a serem desenvolvidas no decorrer do próximo exercício e relatando o resultado ou andamento de todas as atividades desenvolvidas por esta unidade no exercício anterior, mensurando os resultados obtidos de modo a aperfeiçoar as futuras atividades de auditoria (Rodrigues, 2019). Tais relatórios de auditoria interna são utilizados também pelo Conselho Universitário para a tomada de decisões estratégicas na universidade, pois possuem apropriadas e suficientes evidências de informações (Pinheiro \& Oliva, 2020).

Estes aspectos da atuação da AUDIN visando assegurar o cumprimento da legislação existente, bem como dos regulamentos e normas internas estão em consonância com o seu papel de promover transparência das Entidades de Ensino Superior e de coordenar e (ou) apoiar as atividades de comunicação e informação entre os órgãos de gestão e os auditores externos (Fonseca et al., 2020).

Quanto à realização de atividades envolvendo assessoramento aos gestores tendo como finalidade auxiliar preventivamente na tomada de decisões, visando assegurar a adequação dos atos de gestão à legislação e aos resultados quanto à economicidade, eficiência e eficácia da gestão orçamentária, financeira, patrimonial e de pessoal. Em 32 universidades foram planejadas e realizadas tais atividades, realçando o papel estratégico da AUDIN como instância interna de apoio à governança da universidade (Pinheiro \& Oliva, 2020).

Tais resultados mostram que a atividade de auditoria interna pode ser entendida pela maioria dos gestores com caráter de orientação e de auxílio e não como de fiscalizar e de inibir a autonomia da entidade (Dias et al., 2020).

No tocante à realização de auditorias, a avaliação dos riscos de controles internos com a Folha de Pagamento foi a atividade mais evidenciada, sendo executada em 51 (85,00\%) universidades, em consonância com os achados de Farias et al. (2012) ao analisarem as auditorias realizadas na área de Gestão de Recursos Humanos das universidades.

Em 39 (65,00\%) universidades, foram realizadas atividades para verificar a formalização dos convênios e contratos realizados no âmbito das universidades, de forma a assegurar o atendimento às exigências legais pertinentes, por meio da análise de suas respectivas prestações de contas, tendo como resultado esperado a correta formalização dos contratos administrativos. O cumprimento da legislação existente é um pilar do papel da AUDIN como ferramenta de promoção da accountability no processo de transparência na prestação de contas (Fonseca et al., 2020).

A Reserva Técnica para atendimento de ações não contempladas no PAINT, assim como eventuais readequações nos cronogramas das ações programadas, foi planejado em 21 (35,00\%) entidades, no entanto, somente em $13(21,67 \%)$ foi evidenciada no RAINT a utilização desta reserva para realização de atividades extraordinárias, nas demais não foram evidenciadas no RAINT, a utilização ou não. Frise-se que é importante possuir tal reserva no planejamento dado que as atividades da AUDIN têm caráter dinâmico e sempre direcionando o foco para os resultados organizacionais e na melhoria da eficiência da gestão e da qualidade dos seus serviços prestados à instituição (Dias et al., 2020; Rodrigues, 2019).

\section{ConSIDERAÇÕES FINAIS}

O trabalho executado pela AUDIN procura permear as atividades da entidade, de forma a obter uma visão mais completa dos procedimentos administrativos, sempre com o intuito de agregar valor à gestão e assessorar a administração, realçando assim a sua importância na entidade e justificando a sua existência e necessidade de funcionamento.

O objetivo deste estudo consistiu em analisar a atuação da AUDIN no âmbito das universidades federais brasileiras, do ponto de vista da própria unidade, para tal, entendeu-se que era necessário compreender os métodos empregados para a definição de quais atividades seriam realizadas pelas AUDINs e, posteriormente, analisar as atividades planejadas e realizadas por elas, conforme constavam em seus relatórios de atividades. 
A construção da Matriz de Risco contou com a participação dos gestores no processo de planejamento das atividades somente em $21,67 \%$ das entidades, situação que deve ser alterada pois a elaboração de um plano de auditoria mais robusto consiste em um conhecimento mais holístico da instituição, coadunando com a visão do auditor e do auditado na busca de empreender ações e programas para a melhoria da gestão. Sendo os gestores cônscios dos riscos envolvidos em suas unidades, poderão alocar melhor os recursos disponíveis e estabelecer um tratamento condizente com possíveis dificuldades na execução do planejamento. A compreensão dos riscos e a busca de melhoria nos controles internos relacionados a cada atividade resultam no melhor funcionamento dos setores da entidade e, por conseguinte, da própria instituição.

Quanto a analisar as atividades planejadas e realizadas, tem-se que, no ano de 2016, 38,64\% das atividades desenvolvidas pelas AUDINs estavam relacionadas ao assessoramento a gestores e acompanhamento da implementação de recomendações dos órgãos de controle interno e externo e emissão de relatórios, promovendo a transparência ativa por parte desta unidade.

As poucas universidades que demonstraram no RAINT os resultados das ações das auditorias realizadas fizeram-no de uma forma na qual não ficou compreensível quais as conclusões, melhorias e recomendações propostas após a finalização dos trabalhos, ficando o relatório sem demonstrar a eficácia e efetividade do planejamento efetuado no PAINT, pois neste é para ser demonstrado todo o processo de planejamento, hierarquização e seleção das atividades a serem realizadas e no RAINT deve constar a demonstração das atividades realizadas e os resultados alcançados. Tal insuficiência pode ser suprida com a apresentação no RAINT dos relatórios de auditoria, de uma forma coesa, simples e objetiva, dos resultados alcançados confrontando com os objetivos evidenciados no PAINT e assim tais relatórios não atenderiam somente o aspecto legal, mas como instrumentos de transparência das atividades realizadas e promoção de accountability às demais partes interessadas. Entende-se que há um processo de implantação e adaptação no atendimento aos normativos e que nas próximas pesquisas, estes relatórios demonstrem melhor os trabalhos nela produzidos.

As AUDINs vêm pautando a sua atuação na melhoria da eficiência da gestão e da qualidade dos seus serviços prestados à instituição, atendendo assim às recomendações emanadas nos normativos de órgãos reguladores, bem como da literatura acadêmica. Retratando tal evolução, a AUDIN deve refletir sobre a adoção de estratégias e práticas para que atue mais como instância interna de apoio à governança nos órgãos, buscando desenvolver o SCI, com o fito de aperfeiçoá-lo, e o assessoramento à alta gestão, tanto no processo de tomada de decisões como no cumprimento de objetivos e metas, pois transformam a AUDIN em uma ferramenta proativa produzindo informações e relatos gerenciais, conforme a demanda necessária.

Em virtude dos resultados encontrados nesta pesquisa, conclui-se que a institucionalização das atividades desenvolvidas nas AUDINs auxiliam as universidades federais brasileiras e os seus gestores no tocante ao atendimento das recomendações emanadas pelos órgãos de controle, bem como assessoram as demais unidades no processo de tomada de decisões, visando incorporar a adoção de melhores práticas e assim aperfeiçoar o processo de governança das instituições, assegurando a adequação dos atos de gestão à legislação e aos resultados quanto à economicidade, eficiência e eficácia da gestão orçamentária, financeira, patrimonial e de pessoal.

Como limitação da presente pesquisa, tem-se que foi realizada análise das autodeclaradas atividades evidenciadas no PAINT e RAINT, podendo assim existir atividades não registradas nestes relatórios e, portanto, "invisíveis" e não analisadas nesta pesquisa, afetando a transparência e reconhecimento dos fenômenos organizacionais relacionados. Também não foi possível analisar o possível alinhamento da atuação da AUDIN com o Planejamento Estratégico da entidade e outros fatores ou partes interessadas que interfiram na atuação desta unidade, assim como a eficiência e a efetividade das suas atividades.

Às pesquisas futuras, recomenda-se estudar sobre a análise consolidada acerca do nível de maturação dos controles internos dos órgãos da Administração Pública Federal. Também propõe-se realizar pesquisa visando identificar o alinhamento da atuação da AUDIN com o Planejamento estratégico da entidade, assim como identificar quais as partes interessadas e como estas influenciam no desenvolvimento das 
atividades desta unidade. Sugere-se também que sejam criados mecanismos que permitam mensurar a eficácia e efetividade das melhorias e recomendações propostas pela AUDIN após a finalização das auditorias nos setores e como são refletidas na gestão da entidade.

\section{REFERÊNCIAS}

Alzeban, A., Gwilliam, D. (2014) Factors affecting the internal audit effectiveness: A survey of the Saudi public sector. Journal of International Accounting Auditing and Taxation. V.23, 74 - 89. http://dx.doi.org/10.1016/j.intacc audtax.2014.06.001

Arena, M., Azzone, G. (2009) Identifying Organizational Drivers of Internal Audit Effectiveness. International Journal of Auditing. V. 13, 43-60. https://doi.org/10.1111/j.1099-1123.2008.00392.x

Beuren, I. M. (Org.). (2014). Como elaborar trabalhos monográficos em contabilidade: teoria e prática. São Paulo: Atlas.

Beuren, I. M., Zonatto, V. C. S. (2014). Perfil dos artigos sobre controle interno no setor público em periódicos nacionais e internacionais. Revista da Administração Pública. 48(5), 1135-1163, doi: http://dx.doi.org/10.159 $0 / 0034-76121527$

Brito, G. C. de, Pimenta, D. P., Souza, E. M. S. de, Cruz, A. F. da (2017). Benefícios e desafios na implantação da auditoria baseada em risco em instituições federais de ensino. Revista Gestão Universitária na América LatinaGUAL, 10(4), 109-133. https://doi.org/10.5007/1983-4535.2017v10n4p109

Castro, D. P. (2015) Auditoria, contabilidade e controle interno no setor público: integração das áreas do ciclo de gestão. (6. ed.) São Paulo: Atlas.

Chacón, J. I. A. (2015). Auditoria Governamental e tipos de serviços de Auditoria prestados pela equipe de Auditoria Governamental. Revista de Contabilidade e Controladoria, 7(2), 127-143.

Chaves, R. S. (2011). Auditoria e controladoria no setor público. (2. ed.) Curitiba: Juruá.

Cruz, F. da (2007). Auditoria Governamental. (3. ed.) São Paulo: Atlas.

Dias, L., Gomes, D., Angonese, R., Quintana, A. (2020). Auditoria interna e gestão: estudo de caso em uma universidade federal à luz da teoria institucional. Revista Gestão Universitária na América Latina - GUAL, 13(2), 116-139. https://doi.org/10.5007/1983-4535.2020v13n2p116

DiMaggio, P. J., Powell, W. W. (1991). The new institutionalism in organisational analysis. University of Chicago press.

Farias, S., Schulz, J. P., Bellato, R. L., Alberton, L. (2012). A auditoria e os procedimentos de amostragem nas instituições federais de ensino superior da região sul do Brasil: aspectos gerais e específicos ao ano de 2010. Revista Contemporânea de Contabilidade, 9(18),23-40. Recuperado em 23 de Julho, 2020 de https://www.redalyc.org /articulo.oa?id=762/76224786002

Fonseca, A., Jorge, S., Nascimento, C. (2020). O papel da auditoria interna na promoção da accountability nas Instituições de Ensino Superior. Revista de Administração Pública, 54(2), 243-265. Recuperado em 20 julho, $2020 \mathrm{de} \mathrm{http://bibliotecadigital.fgv.br/ojs/index.php/rap/article/view/81250/77587}$

Instrução Normativa n. 24, de 17 de novembro de 2015. Dispõe sobre o Plano Anual de Auditoria Interna (PAINT), os trabalhos de auditoria realizados pelas unidades de auditoria interna e o Relatório Anual de Atividades da Auditoria Interna (RAINT) e dá outras providências. Brasília: CGU. Recuperado em 20 de outubro, 2016, de https://goo.gl/senYVZ

Instrução Normativa Conjunta $n^{\circ}$ 01, de 10 de maio de 2016. Dispõe sobre controles internos, gestão de riscos e governança no âmbito do Poder Executivo federal. Brasília: CGU. Recuperado em 20 outubro, 2016, de http s://goo.gl/XSznFs

Instrução Normativa n. 09, de 09 de outubro de 2018. Dispõe sobre o Plano Anual de Auditoria Interna - PAINT e sobre o Relatório Anual de Atividades de Auditoria Interna - RAINT das Unidades de Auditoria Interna Governamental do Poder Executivo Federal e dá outras providências. Brasília: CGU. Recuperado em 20 de outubro, 2019, de https://goo.gl/senYVZ. 
Rubens Carlos Rodrigues, et al. Atuação da Auditoria Interna nas Universidades Federais Brasileira...

KMPG (2017). Gerenciamento de riscos: Os principais fatores de risco apresentados pelas empresas abertas brasileiras. São Paulo: KPMG.

Mafra, M. S., Suave, R., Guilherme, J. T., Alberton, L. (2016). Características da literatura internacional sobre auditoria governamental. Gestão e Sociedade, 9(23), 926-945. https://doi.org/10.21171/ges.v9i23.1888

Moreira, P. A., Palmisano, A. (2016). Transparência: um princípio de governança corporativa na auditoria de recursos públicos federais. Revista Metropolitana de Governança Corporativa , 1(1) 3-25. Recuperado em 31 janeiro, 2017, de https://goo.gl/97VmJt

Peter, M. da G. A., Machado, M.V. V. (2014). Manual de Auditoria Governamental. (2. ed.) São Paulo: Atlas.

Pickett, K. H. S. (2005). The essential handbook of internal auditing. Chichester: John Willey \& Sons.

Pinheiro, D. R., Oliva, E. C. (2020). A atuação da auditoria interna na governança pública: um estudo baseado na visão da alta administração das universidades públicas federais brasileiras. Contabilidade Vista \& Revista, 31(2). http s://doi.org/10.22561/cvr.v31i2.4933

Power, M. K. (2003). Auditing and the production of legitimacy. Accounting, organizations and society, 28(4), 379-394. https://doi.org/10.1016/S0361-3682(01)00047-2

Power, M. (2021). Modelling the Micro-Foundations of the Audit Society: Organizations and the Logic of the Audit Trail. Academy of Management Review, 46(1), 6-32. https://doi.org/10.5465/amr.2017.0212

Rodrigues, R. C. (2019). Métodos adotados na Administração Pública para elaborar Matrizes de Risco. RAGC, 7(30), 96-112.

Silva, S. R., Sena, R. A. (2019). O Planejamento da Auditoria Interna dentro das Organizações/Internal Audit Planning Within Organizations. ID on line REVISTA MULTIDISCIPLINA DE PSICOLOGIA, 13(47), 595-606. https://doi.org/10.14295/idonline.v13i47.2051 